CLINICAL STUDY

\title{
Effect of parathyroidectomy on subclinical cardiovascular disease in mild primary hyperparathyroidism
}

\author{
M D Walker, T Rundek ${ }^{1}$, S Homma, M DiTullio, S Iwata, J A Lee ${ }^{2}$, J Choi ${ }^{3}$, R Liu, C Zhang, D J McMahon, R L Sacco ${ }^{1}$ \\ and S J Silverberg \\ Department of Medicine, Columbia University College of Physicians and Surgeons, 630 West 168th Street, PH8 West-864, New York, New York 10032, \\ USA, ${ }^{1}$ Department of Neurology, University of Miami, Miami, Florida, USA, Departments of ${ }^{2}$ Surgery and ${ }^{3}$ Neurology, Columbia University College of \\ Physicians and Surgeons, New York, New York, USA \\ (Correspondence should be addressed to MD Walker; Email: mad2037@columbia.edu)
}

\begin{abstract}
Objective: We recently demonstrated that mild primary hyperparathyroidism (PHPT) is associated with increased carotid intima-media thickness (IMT) and stiffness, and increased aortic valve calcification. It is unclear whether parathyroidectomy (PTX) improves these abnormalities. The purpose of this study was to determine whether cardiovascular abnormalities in PHPT improve with PTX.

Design: Forty-four patients with PHPT were studied using carotid ultrasound and transthoracic echocardiography before and after PTX. Carotid IMT, carotid plaque and stiffness, left ventricular mass index (LVMI), myocardial and valvular calcification, and diastolic function were measured before, 1- and 2-year post-PTX.

Results: Two years after PTX, increased carotid stiffness tended to decline to the normal range (17\%, $P=0.056$ ) while elevated carotid IMT did not improve. Carotid plaque number and thickness, LVMI and cardiac calcifications did not change after PTX, while some measures of diastolic function (isovolumic relaxation time (IVRT) and tissue Doppler peak early diastolic velocity) worsened within the normal range. Indices did improve in patients with cardiovascular abnormalities at baseline. Increased carotid stiffness improved by $28 \%(P=0.004)$, a decline likely to be of clinical significance. More limited improvements also occurred in elevated IMT $(3 \%, P=0.017)$ and abnormal IVRT $(13 \%, P<0.05)$, a measure of diastolic dysfunction.

Conclusions: In mild PHPT, PTX led to modest changes in some cardiovascular indices. Improvements were mainly evident in those with preexisting cardiovascular abnormalities, particularly elevated carotid stiffness. These findings are reassuring with regard to current international guidelines that do not include cardiovascular disease as a criterion for PTX.
\end{abstract}

European Journal of Endocrinology 167 277-285

\section{Introduction}

Classical primary hyperparathyroidism (PHPT), a symptomatic disease characterized by marked hypercalcemia, nephrolithiasis, and overt skeletal disease, was also associated with increased cardiovascular morbidity and mortality $(1,2)$. Today, most patients are asymptomatic and have mild hypercalcemia that is often an incidental finding on routine biochemical testing (3). Some studies of patients with the modern phenotype of PHPT have continued to report increased cardiovascular mortality, while others have not $(4,5)$. There is evidence for subclinical cardiovascular disease in mild PHPT, but data on its extent and reversibility are too limited to provide a comprehensive characterization of these problems $(6,7)$. After systematic review of the available literature, the Third International Workshop on PHPT in 2008 emphasized the need to determine whether there are 'significant reversible cardiovascular abnormalities' in mild PHPT as this could 'change the recommendations for parathyroidectomy' (PTX) and influence the cardiovascular health of patients with mild PHPT (8). As many asymptomatic patients are monitored without surgical intervention, data regarding the impact of mild PHPT and its cure on cardiovascular health are particularly important to obtain (3).

We have recently reported that patients with mild PHPT (serum calcium $<3.0 \mathrm{mmol} / \mathrm{l}(<12 \mathrm{mg} / \mathrm{dl})$ ) have subclinical carotid vascular abnormalities and increased aortic valve calcification area but normal left ventricular mass index (LVMI) and cardiac function (6, 7, 9). Carotid intima-media thickness (IMT) and plaque thickness (both measures of the burden of atherosclerosis) as well as carotid stiffness were elevated in those with PHPT compared with population-based normative data. There are limited data regarding regression of carotid IMT, plaque or stiffness after PTX 
in mild PHPT, and of clinical importance, none specific to PHPT patients with carotid disease present before surgery. Likewise, results from studies assessing changes in cardiac structure and function after PTX in mild PHPT are also sparse and conflicting (10, 11, 12, 13, $14,15)$. This investigation was designed to determine the effect of PTX on carotid and cardiac indices known to be associated with or predict cardiovascular outcomes $(16,17,18,19,20,21,22,23,24)$. The current study represents the prospective follow-up of those participants in our previous study who underwent PTX over a 2-year period $(6,7,9)$.

\section{Materials and methods}

PHPT patients were assessed pre-PTX and measures of cardiovascular structure and function were evaluated prospectively for 2 years following PTX. All participants gave written, informed consent. This study was approved by the Institutional Review Board of Columbia University Medical Center.

\section{Subjects}

The current cohort represents the 44 PHPT patients, enrolled in the parent study as described previously $(6,7)$, who had curative PTX. Patients were between 45 and 75 years, had serum calcium $>2.55$ but $<3.0 \mathrm{mmol} / \mathrm{l}(>10.2$ but $<12.0 \mathrm{mg} / \mathrm{dl})$ and an elevated or inappropriately normal parathyroid hormone (PTH) level. Exclusion criteria included familial hypocalciuric hypercalcemia, thiazide- or lithiuminduced hyperparathyroidism, bisphosphonate use, and initiation of changes in cholesterol-lowering medications within 2 years of study entry. Lipidlowering medications were adjusted during the study if deemed necessary by each participant's primary doctor. History of cardiovascular risk factors (including race/ethnicity, coronary artery disease hypercholesterolemia, hypertension, diabetes mellitus, and cigarette smoking) was obtained as described $(6,7)$.

\section{Biochemical evaluation}

Fasting serum was obtained for calcium, albumin, phosphorus, glucose, total cholesterol, HDL and triglycerides (measured by an automated analyzer). LDL was calculated (25). PTH was measured by immunochemiluminometric assay for intact PTH (Scantibodies Laboratories, Santee, CA, USA; detects PTH(1-84) and PTH(7-84)). 25-Hydroxyvitamin D (250HD) was measured by liquid chromatography/ tandem mass spectrometry (Mayo Clinic, Rochester, MN, USA). 1,25-Dihydroxyvitamin D (1,25-(OH) $\left.{ }_{2} \mathrm{D}\right)$ was measured by RIA (Diasorin, Stillwater, MN, USA). Insulin was measured by RIA (Siemens Healthcare Diagnostics, Los Angeles, CA, USA). C-reactive protein, a biochemical marker of inflammation that reflects cardiovascular risk, was measured using a particle enhanced turbidimetric assay (Roche Diagnostics; reference range $<47.6 \mathrm{nmol} / \mathrm{l})$. The homeostatic model assessment of insulin resistance (HOMA-IR) was calculated (26) to determine whether PTX improves insulin resistance, a known cardiovascular risk factor. Estimated glomerular filtration rate (GFR) was calculated using the Modification of Diet in Renal Disease equation (27).

\section{Carotid ultrasonography}

High-resolution B-mode carotid ultrasound was performed using a GE LogIQ 700 system (GE Healthcare, Milwaukee, WI, USA) with a multifrequency 9/13 MHz transducer as described previously $(6,28)$. The reliability of measures has previously been described (28). Intraclass correlation coefficients for all indices are very high (0.94-0.96). Readings were performed by a single trained research sonologist. Carotid IMT was measured according to our Northern Manhattan Study (NOMAS) validated protocol $(28,29)$ as a composite measure of the near and far wall IMT of the common carotid artery (CCA), bifurcation, and internal carotid artery from both sides of the neck. IMT $\geq 0.9 \mathrm{~mm}$ was considered abnormal (threshold for increased cardiovascular risk in the Cardiovascular Health Study (21)). Carotid plaque in any of the carotid artery segments (the CCA, bifurcation, and internal carotid artery) was defined as an area of focal wall thickening more than $50 \%$ greater than the surrounding wall thickness. Maximal carotid plaque thickness (MCPT) was measured by a single trained sonographer at the highest plaque prominence (Image-Pro V.5.2 software Microsoft Corporation). Carotid stiffness was measured in the $10 \mathrm{~mm}$ segment of the right CCA below the origin of the carotid bulb from at least five consecutive cardiac cycles on the B/M-mode imaging recordings (Image Pro software). The systolic (SD) and diastolic diameters (DD) were measured and the following calculations were made: carotid strain $=(\mathrm{SD}-\mathrm{DD}) / \mathrm{DD}$; and stiffness $=\ln (\mathrm{SBP} / \mathrm{DBP}) /$ strain. Higher stiffness indicates reduced arterial distensibility or compliance (abnormal: $\geq 6$, the 75 th percentile in the NOMAS cohort $(n=2000)$ for the study age range).

\section{Transthoracic echocardiography}

Transthoracic echocardiography was performed according to the guidelines of the American Society of Echocardiography (30). LV diastolic dimension (LVDD), interventricular septal thickness (IVS), and posterior wall thickness (PWT) were measured. Left ventricular mass (LVM) was calculated as: 0.8 (1.04 (LVDD+ IVS + PWT $\left.)^{3}\right)+0.6(31)$. LVMI was calculated as LVM divided by body surface area (abnormal: women $>108 \mathrm{~g} / \mathrm{m}^{2}$, men $\left.>131 \mathrm{~g} / \mathrm{m}^{2}(30)\right)$. Transmitral 
diastolic flow by pulsed-wave Doppler and myocardial velocity by tissue Doppler were obtained from an apical four-chamber view using standardized techniques (32), and the following were determined: peak velocities of the early (E wave) and late (A wave) phase of the mitral inflow pattern, and their ratio (E/A); deceleration time of $\mathrm{E}$ wave; isovolumic relaxation time (IVRT); and peak early $\left(\mathrm{e}^{\prime}\right)$ diastolic velocity of the lateral mitral annulus. Presence of calcification was assessed in the mitral annulus at the junction of the atrioventricular groove and the posterior or anterior mitral leaflet; the number of calcifications in left ventricular myocardium were evaluated using fundamental nonharmonic images in the apical four-chamber view at end-systole. In the aortic valve, a more sophisticated technique allowed measurement of calcification area for each aortic valve leaflet, and the sum of all leaflets were also measured by a single investigator as described previously (9).

\section{Statistical analysis}

Participant characteristics and cardiovascular risk factors are described by number, percentages, or mean value \pm s.D. All carotid and echocardiographic outcomes were prespecified and no changes to the methods were made after study commencement, except for the addition of a new methodology for assessing aortic valve calcification area (9). Changes in cardiovascular indices over time were assessed with linear mixed models for repeated measures. All models included a fixed effect for time and an autoregressive covariance structure for the within-subject autocorrelation between times. A compound symmetry structure was used for serum 250HD. Results from linear mixed models are reported as model-estimated means \pm s.E.M. and comparison of means at different times used the method of simultaneous 95\% confidence intervals for the between-time difference. All 44 baseline participants who had PTX were included in the analysis regardless of follow-up: three patients were lost to follow-up at 12 months and an additional three patients were lost to follow-up at 24 months. Cardiovascular risk factors, serum calcium, PTH, and 250HD did not differ between those who completed the study vs those who dropped out. Within linear mixed models, individuals lost to follow-up contribute partial information based on their available data. In order to ensure that we had not introduced bias by including individuals lost to follow-up in the analysis, we repeated the analysis limited to the 38 subjects on whom complete data were available. The direction and significance of results did not differ (data not shown). To account for changes in lipid-lowering medications, analyses were repeated excluding individuals who initiated or changed formulations of lipid-lowering medications. Pearson correlation was used to assess the association between continuous variables. We assessed correlations between biochemical variables that significantly changed over time (calcium, PTH,
250HD, and glucose) and change in cardiovascular measures. Power calculations indicated that 40 participants were needed to detect a $10 \%$ change in cardiovascular structural and functional measures with $80 \%$ power and $5 \%$ type 1 error rate assuming a within-subject repeated measures ANCOVA analysis. Statistical analysis was performed using SAS version 9.2 (SAS Institute, Cary, NC, USA). A $P$ value $<0.05$ was considered statistically significant.

\section{Results}

\section{Clinical and biochemical data}

Consistent with the diagnosis of PHPT, participants were predominantly female (Table 1) and had biochemical evidence typical of mild PHPT (serum calcium $($ mean \pm s.D. $): 2.62 \pm 0.2 \mathrm{mmol} / \mathrm{l} \quad(10.5 \pm 0.7 \mathrm{mg} / \mathrm{dl})$, normal $2.18-2.55 \mathrm{mmol} / \mathrm{l}$ (8.7-10.2 mg/dl); PTH: $97 \pm 33$, normal 10-66 ng/l). Mean time elapsed from diagnosis of PHPT was $43 \pm 59$ months. All participants were white and four were Hispanic. Cardiovascular risk factors at baseline are shown in Table 1. Over one-third of patients had hypertension and hyperlipidemia, but blood pressure and cholesterol levels were wellcontrolled. Thirty percent were taking lipid-lowering medications and six participants had changes in cholesterol medications during the study (initiation $(n=2)$, discontinuation $(n=2)$, and dosage or formulation change $(n=2))$.

Of the 44 patients, 28 (64\%) met one or more of the 2002 NIH guidelines for PTX, while the rest chose to have surgery despite not meeting surgical guidelines. Criteria for PTX included: nephrolithiasis in nine

Table 1 Participants' characteristics and cardiovascular risk factors.

\begin{tabular}{lc}
\hline & $\begin{array}{c}\text { PHPT }(n=44) \\
\text { Variables }\end{array}$ \\
\hline Age (years) & $62 \pm$ s.D. or percentage \\
Female (\%) & $80(n=35)$ \\
Height $(\mathrm{cm})$ & $163 \pm 8$ \\
Weight $(\mathrm{kg})$ & $68.2 \pm 13.2$ \\
BMl $\left(\mathrm{kg} / \mathrm{m}^{2}\right)$ & $26 \pm 4$ \\
Coronary artery disease (\%) & $2(n=1)$ \\
Hypercholesterolemia (\%) & $36(n=16)$ \\
Hypertension (\%) & $34(n=15)$ \\
Diabetes (\%) & $2(n=1)$ \\
Tobacco current use (\%) & $5(n=2)$ \\
Systolic blood pressure (mmHg) & $123 \pm 16$ \\
Diastolic blood pressure (mmHg) & $74 \pm 10$ \\
Estimated GFR (ml/min per & $83 \pm 20$ \\
1.73 m ${ }^{2}$ ) & \\
Total cholesterol (mg/dl) & $221 \pm 34$ \\
HDL (mg/dl) & $62 \pm 17$ \\
LDL (mg/dl) & $140 \pm 28$ \\
Triglycerides (mg/dl) & $96 \pm 39$ \\
\hline
\end{tabular}


patients $(20 \%)$, serum calcium $>0.25 \mathrm{mmol} / \mathrm{l}$ above upper limit of normal in five patients (11\%), urinary calcium $>10 \mathrm{mmol} / 24 \mathrm{~h}$ in seven patients (16\%), osteoporosis at any site in 18 patients $(41 \%)$, and age $<50$ years in two patients (5\%). After PTX (Table 2), serum calcium and PTH levels normalized and remained stable. 250HD increased after PTX, while $1,25-(\mathrm{OHD})_{2}$ levels were transiently lower at 1 but not at 2 years. Lipid levels did not change. BMI increased by $0.6 \pm 0.1 \mathrm{~kg} / \mathrm{m}^{2}$ at 1 year and remained above baseline $(P<0.01$ of 1 and 2 years $)$. Fasting glucose decreased within the normal range, without an accompanying change in insulin or HOMA-IR. Estimated GFR declined at 1 year $(P=0.002)$ and remained below baseline at 2 years $(P=0.01)$. C-reactive protein increased within the normal range by 1 year $(P=0.01)$ and remained above baseline 2 years post-PTX $(P=0.006)$.

\section{Carotid structure and function}

Baseline blood pressure was normal and did not change over the 2-year follow-up period (Table 3). Two carotid indices, carotid IMT and carotid stiffness, were abnormal at baseline. Although values decreased within the second postoperative year compared with 12-month values, at 2 years IMT was not significantly different from baseline. Carotid stiffness tended to decline by $17 \%$, such that mean levels of carotid stiffness were within the normal range by 2 years $(P=0.056)$. Change in IMT and stiffness was not associated with baseline values or postoperative change in serum calcium, PTH, 250HD, or glucose concentrations. Plaque number and maximal carotid plaque thickness were unchanged after PTX.

\section{Cardiac structure and function}

LVM and diastolic function were normal at baseline (Table 4). LVMI and myocardial and mitral calcifications did not decline after PTX. Aortic valve calcification area increased by $5 \%$ at 1 year post-PTX and remained above baseline $(P<0.01$ for both) at 2 years. Some measures of diastolic function (IVRT and tissue Doppler $\mathrm{e}^{\prime}$; Table 4) tended to worsen within the normal range, while others did not change (deceleration time and E/A). Changes in cardiac indices were not associated with baseline calcium, PTH, or $250 \mathrm{HD}$ or with changes in these biochemistries postoperatively.

\section{Post-PTX changes in those with baseline cardiovascular abnormalities}

A prespecified analysis assessed the effect of PTX on cardiovascular indices in those with abnormal vs normal indices at baseline. The effect of time was different between those with abnormal vs normal IMT $(P=0.01)$ and IVRT $(P<0.001)$ and tended to differ $(P=0.053)$ between those with abnormal vs normal carotid stiffness. The improvements in those with abnormal IMT, carotid stiffness, and IVRT (described below) were not associated with baseline values or change in levels of calcium, PTH, or $250 \mathrm{HD}$.

IMT was abnormal in $32(73 \%)$ patients at baseline and improved by $3 \%$ at 2 years in this subgroup, though mean levels did not normalize (Fig. $1 \mathrm{~A}, P=0.017$ ). This improvement persisted after excluding four individuals who initiated or changed formulations of lipid-lowering medications $(P=0.043)$. In contrast, IMT increased at 12 months $(P=0.003)$ in those with normal preoperative values but returned to baseline by 24 -months $(P=0.29)$.

Table 2 Longitudinal changes in biochemistry after parathyroidectomy. Values represent least squares means \pm S.E.M.

\begin{tabular}{|c|c|c|c|c|}
\hline & Baseline & 12 Months & 24 Months & $\begin{array}{l}\text { Normal } \\
\text { values }\end{array}$ \\
\hline Calcium (mmol/l) & $2.62 \pm 0.03$ & $2.33 \pm 0.03^{\star}$ & $2.23 \pm 0.03^{*}$ & $2.18-2.55$ \\
\hline PTH (ng/l) & $97 \pm 5$ & $34 \pm 5^{*}$ & $34 \pm 5^{\star}$ & $10-66$ \\
\hline Phosphorus (mmol/l) & $0.90 \pm 0.03$ & $1.13 \pm 0.03^{*}$ & $1.16 \pm 0.03^{*}$ & $0.81-1.45$ \\
\hline $25-\mathrm{OH}$ vitamin $\mathrm{D}(\mathrm{nmol} / \mathrm{l})$ & $70 \pm 4$ & $95 \pm 4^{*}$ & $100 \pm 5^{\star}$ & $75-250$ \\
\hline $1,25-(\mathrm{OHD})_{2}$ vitamin $\mathrm{D}(\mathrm{pmol} / \mathrm{l})$ & $174 \pm 10$ & $112 \pm 10^{\ddagger}$ & $161 \pm 10$ & $49-174$ \\
\hline Total cholesterol (mmol//) & $5.72 \pm 0.16$ & $5.80 \pm 0.16$ & $5.91 \pm 0.16$ & $<5.18$ \\
\hline $\mathrm{LDL}(\mathrm{mmol} / \mathrm{l})$ & $3.63 \pm 0.13$ & $3.65 \pm 0.13$ & $3.78 \pm 0.13$ & $<2.59$ \\
\hline $\mathrm{HDL}(\mathrm{mmol} / \mathrm{l})$ & $1.61 \pm 0.05$ & $1.58 \pm 0.08$ & $1.58 \pm 0.08$ & $>1.01$ \\
\hline Triglycerides (mmol/l) & $2.49 \pm 0.21$ & $2.80 \pm 0.21$ & $2.64 \pm 0.21$ & $<3.63$ \\
\hline Glucose (mmol/l) & $5.33 \pm 0.11$ & $5.22 \pm 0.11$ & $5.00 \pm 0.11^{\ddagger, \S}$ & $<5.55$ \\
\hline Insulin (pmol/l) & $59 \pm 10$ & $63 \pm 10$ & $54 \pm 10$ & $<204$ \\
\hline HOMA-IR & $2.2 \pm 0.4$ & $2.2 \pm 0.4$ & $1.7 \pm 0.4$ & 1.0 \\
\hline C-reactive protein (nmol/l) & $13.3 \pm 4.8$ & $25.7 \pm 4.8^{\ddagger}$ & $29.5 \pm 4.8^{\ddagger}$ & $<47.6 \mathrm{mg} / \mathrm{l}$ \\
\hline $\begin{array}{l}\text { Estimated GFR ( } \mathrm{ml} / \mathrm{min} \text { per } \\
\left.1.78 \mathrm{~m}^{2}\right)\end{array}$ & $83 \pm 3$ & $77 \pm 3^{\ddagger}$ & $78 \pm 3^{\ddagger}$ & $>59$ \\
\hline
\end{tabular}

${ }^{\star} P<0.001$ compared with baseline; ${ }^{\ddagger} P<0.05$ compared with baseline; ${ }^{\S} P<0.01$ compared with 12 months. 
Table 3 Longitudinal changes in blood pressure and carotid measures. Values represent least squares means \pm S.E.M.

\begin{tabular}{lcccc}
\hline & Baseline $(n=44)$ & 12 Months $(n=41)$ & 24 Months $(n=38)$ & Normal range \\
\hline Systolic BP $(\mathrm{mmHg})$ & $123 \pm 2.3$ & $122 \pm 2.4$ & $125 \pm 2.6$ & $<140$ \\
Diastolic BP $(\mathrm{mmHg})$ & $74 \pm 1$ & $76 \pm 1$ & $78 \pm 2$ & $<90$ \\
IMT $(\mathrm{mm})$ & $0.961 \pm 0.007$ & $0.971 \pm 0.008$ & $0.946 \pm 0.008^{\star}$ & $0.7-0.9$ \\
$\mathrm{MCPT}^{\mathrm{a}}(\mathrm{mm})$ & $0.89 \pm 0.07$ & $1.07 \pm 0.07^{\dagger}$ & $1.00 \pm 0.07$ & \\
Plaque number $_{\text {a }}$ & $0.95 \pm 0.24$ & $1.19 \pm 0.24^{\ddagger}$ & $1.14 \pm 0.24$ & \\
Stiffness & $6.3 \pm 0.4$ & $6.4 \pm 0.4$ & $5.2 \pm 0.4^{*}$, & $<6$ \\
\hline
\end{tabular}

$\mathrm{BP}$, blood pressure; IMT, intima-media thickness; MCPT, maximal carotid plaque thickness. ${ }^{*} P<0.05$ vs 12 months; ${ }^{\dagger} P<0.05$ vs baseline; ${ }^{\ddagger} P<0.01$ vs baseline; ${ }^{\S} P=0.056$ vs baseline.

${ }^{\mathrm{a}}$ Normal range - no plaque.

In the 17 (39\%) patients who had abnormal carotid stiffness at baseline (Fig. 1B), mean stiffness declined by $28 \%$ at 2 years $(P=0.004)$. This improvement persisted after excluding those who initiated or changed formulations of lipid-lowering medications $(P=0.012)$. Stiffness normalized in $47 \%(n=8)$ of participants who were abnormal at baseline. In contrast, there was no change over time in those with normal stiffness.

Diastolic dysfunction was uncommon. Mean IVRT normalized (declining 13\%) in those with abnormal IVRT $(n=8,18 \%)$, while those with normal IVRT at baseline increased within the normal range. Heart rate, which can influence IVRT, did not change in the group with abnormal IVRT ( $66 \pm 3$ vs $70 \pm 4 \mathrm{bpm}, P=0.41$ ). There were no changes compared with baseline in those with abnormal E/A $(n=11)$, tissue Doppler $(n=3)$, or LVMI $(n=6)$. Only one participant had abnormal DT.

After PTX, as in the whole cohort, glucose improved in those with abnormal IMT, stiffness, and IVRT, but the change in glucose did not correlate with observed changes in these indices. Neither blood pressure, estimated GFR, BMI, insulin nor HOMA-IR improved over time in the subgroups with abnormal IMT, stiffness, or IVRT.

\section{Discussion}

We have previously reported that mild PHPT is associated with carotid vascular abnormalities (increased IMT, plaque thickness, and vascular stiffness) and increased aortic valve calcification area, while other cardiac indices including LVMI and diastolic function are normal $(6,7,9)$. We now report that PTX did not ameliorate the structural cardiovascular abnormalities (carotid IMT, carotid plaque presence and thickness, and aortic valve calcification), while vascular compliance (carotid stiffness) tended to improve. As LVM and diastolic function were normal at baseline, improvement in these indices would not necessarily have been expected. In contrast, those with elevated carotid IMT, increased carotid stiffness and prolonged IVRT at baseline did improve after surgery.

There are limited data on the effect of PTX on the carotid vascular bed, the site where we found most abnormalities in mild PHPT and most changes after its cure. Two previous studies did not find improved IMT after surgery despite higher serum calcium levels (2.8 and $3.0 \mathrm{mmol} / \mathrm{l}$ ), although these studies were likely underpowered $(n=27$ and 20). In this study, the greatest effect of PTX was on carotid stiffness. The $17 \%$ improvement in the group as a whole $(P=0.056)$ was due to the impressive $28 \%$ improvement in those with increased vascular stiffness $(P=0.004)$. Increased arterial stiffness not only provides prognostic information regarding cardiovascular risk independent of traditional risk factors including age, sex, blood pressure, cholesterol, diabetes, and smoking (33) but also predicts cardiovascular death and stroke in community-dwelling middle-aged individuals in population-based studies $(34,35)$. Though ours is the first study to address the effect of PTX on carotid stiffness,

Table 4 Transthoracic echocardiography measures. Values represent least squares means \pm S.E.M.

\begin{tabular}{|c|c|c|c|c|}
\hline & Baseline $(n=44)$ & 12 Months $(n=41)$ & 24 Months $(n=38)$ & Normal range \\
\hline $\begin{array}{l}\text { Heart rate (beats/min) } \\
\text { Left ventricular mass index }\left(\mathrm{g} / \mathrm{m}^{2}\right)\end{array}$ & $\begin{array}{l}70 \pm 2 \\
96 \pm 2\end{array}$ & $\begin{array}{l}73 \pm 1 \\
99 \pm 2\end{array}$ & $\begin{array}{r}73 \pm 2 \\
100 \pm 2\end{array}$ & $\begin{array}{l}60-100 \\
q \leq 108 \\
o \leq 131\end{array}$ \\
\hline $\begin{array}{l}\text { Myocardial calcifications }{ }^{\mathrm{a}} \text { (number) } \\
\text { Mitral annular calcification }{ }^{\mathrm{a}}(\%) \\
\text { Aortic valve calcification } \text { area }^{\mathrm{a}}\left(\mathrm{cm}^{2}\right)\end{array}$ & $\begin{array}{l}8.9 \pm 0.4 \\
16 \\
0.249+0.02\end{array}$ & $\begin{array}{l}8.6 \pm 0.4 \\
17 \\
0.262+0.02 *\end{array}$ & $\begin{array}{c}8.9 \pm 0.4 \\
14 \\
0.265+0.02 *\end{array}$ & \\
\hline $\begin{array}{l}\text { IVRT (ms) } \\
\text { IVRT }\end{array}$ & $85.5 \pm 2.3$ & $92.3 \pm 2.4^{\dagger}$ & $99.9 \pm 2.5^{\dagger, \neq}$ & $50-102$ \\
\hline E/A ratio & $1.07 \pm 0.04$ & $1.13 \pm 0.04$ & $1.09 \pm 0.04$ & $0.75-1.5$ \\
\hline Tissue Doppler e' (mm) & $11.4 \pm 0.3$ & $10.3 \pm 0.3^{\dagger}$ & $10.0 \pm 0.3^{\dagger}$ & $\geq 7$ \\
\hline Mitral deceleration time (ms) & $162 \pm 5$ & $168 \pm 4$ & $164 \pm 5$ & $140-220$ \\
\hline
\end{tabular}

${ }^{\star} P<0.01$ vs baseline, ${ }^{\dagger} P<0.05$ vs baseline,${ }^{\ddagger} P<0.05$ vs 12 months.

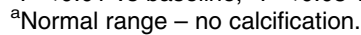




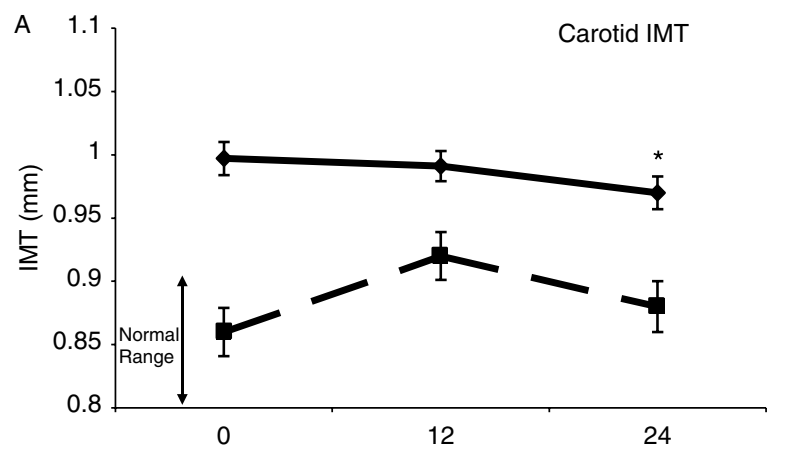

B

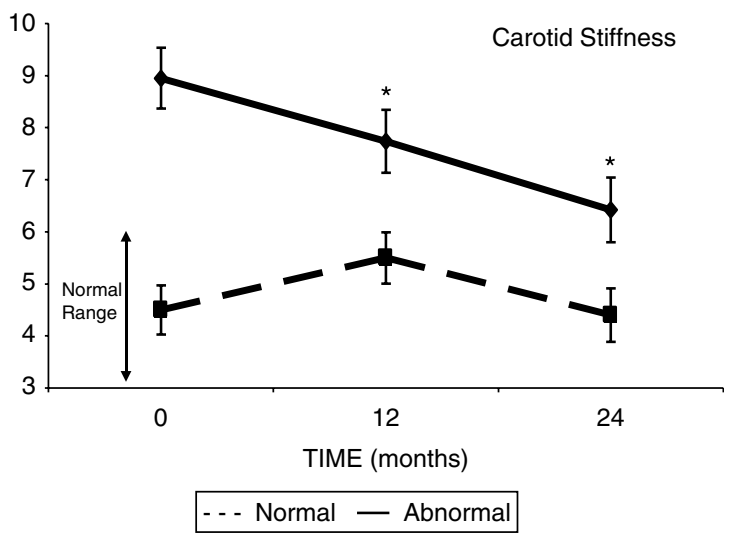

Figure 1 (A) Change in IMT after parathyroidectomy (PTX) in those with abnormal $(\geq 0.9 \mathrm{~mm} ; n=32)$ vs normal $(n=12)$ IMT at baseline. (B) Change in stiffness after PTX in those with abnormal $(\geq 6 ; n=17)$ vs normal $(n=27)$ stiffness at baseline. Data are presented as LS means \pm S.E.M. ${ }^{\star} P<0.05$ compared with baseline value.

our findings are consistent with recent data from a small study $(n=17)$ demonstrating decreased aortic stiffness after PTX (36). Improved arterial stiffness after PTX could reduce cardiovascular risk independently of changes in traditional risk factors. Renal failure patients who responded to medical therapy with decreasing aortic stiffness had a marked survival benefit compared with those without such a decrease (37). Whether the improved vascular function after PTX translates into a reduction in cardiovascular events is unknown. Nor is the biological mechanism clear. Our group and others have reported that PTH levels were positively associated with carotid (6) and aortic stiffness $(38,39)$. As chronic continuous PTH infusion results in vasoconstriction and hypertension $(40,41)$, the PTH reduction after surgery might affect smooth muscle cell proliferation or function, resulting in reduced inflammation and improved vascular function. We did not find that baseline PTH or calcium, or changes in either measure predicted the postoperative decline in stiffness. The narrow range of biochemical abnormalities in this homogeneous study population or the relatively smaller size of this surgical cohort may have limited our ability to detect such an association.
We did not find improvements in cardiac indices after PTX. Several $(10,12,13)$ but not all (11) previous studies on patients with more severe PHPT (mean calcium $2.78-3.0 \mathrm{mmol} / \mathrm{l}$ ) reported regression of elevated mean LVM. In contrast, three studies assessing diastolic function found no improvement $(10,11,12)$. Recent investigations in mild PHPT (mean calcium $2.63-2.65 \mathrm{mmol} / \mathrm{l}$ ) also found normal LVM and diastolic function at baseline and no change after surgery $(14,15)$. Regression of cardiac and valvular calcifications has not been demonstrated in previous studies $(10,42)$. Our finding that aortic valve calcification area, using a more sensitive measure, worsened after PTX is perhaps not surprising, as aortic valve calcification is thought to be an irreversible process once initiated (43). Unfortunately, the design of our study does not allow us to determine whether the rate of progression of aortic valve calcification after PTX is lower than would be expected in PHPT patients folowed without surgery.

Although the number of affected patients was small, the improvements seen in those patients with cardiovascular abnormalities at baseline were of clinical interest. In mild PHPT, there is a precedent for observing the greatest post-PTX improvement in bone mineral density in those with the most abnormal skeletal findings $(44,45)$. In this study, carotid IMT improved in those with increased baseline values, but the decrement was small (3\%) relative to the 20-24\% declines in IMT associated with HMG-CoA reductase inhibitors (which powerfully lower the risk of CV events) (46, 47, 48). Ultimately, mean IMT still remained abnormal after PTX, and the small decline is unlikely to be of clinical relevance. Likewise, the clinical significance of the $13 \%$ improvement in IVRT is unclear for several reasons. First, both the incidence of abnormal IVRT and the extent of improvement were small. Secondly, and more importantly, both baseline and post-PTX values were within the normal range, and there was no consistent benefit across other indices of diastolic function. The small number of participants with abnormalities in these indices may have limited our ability to detect changes, but it further supports the conclusion that diastolic dysfunction is unlikely to be an important feature of PHPT.

While the changes in carotid IMT and IVRT are of uncertain clinical significance, the $28 \%$ decline in carotid stiffness in those with decreased vascular compliance before PTX is likely to be clinically meaningful. First, elevated carotid stiffness normalized in half of all patients. Secondly, the $28 \%$ decline compares favorably with reported improvements in carotid stiffness reported with cardiovascular risk reduction. These include an $18.8 \%$ decline in stiffness in response to a combination of a statin (fluvastatin) and an angiotensin receptor blocker (valsartan) (49); a $27 \%$ decline after 1 year of pravastatin in hypercholesterolemic patients $(50,51)$; and a $37 \%$ decline in a study of 
high-dose atorvastatin. Notably, the post-PTX decline in carotid stiffness observed in our patients was not associated with improved lipid status.

Increased BMI and insulin resistance have been associated with PHPT in some investigations $(52,53)$. A recent randomized study of PTX vs medical observation in mild PHPT found no improvement in BMI, glucose, insulin, markers of insulin resistance, or inflammation (54). The small decline in fasting glucose within the normal range seen in our patients is of questionable clinical significance and was not accompanied by changes in insulin resistance or related to changes in IMT, stiffness, or IVRT. Other cardiovascular risk factors actually worsened after PTX (BMI and CRP increased and estimated GFR declined), effects that we suspect may be related to aging.

The absence of an association between postoperative cardiovascular changes and changes in serum calcium and/or PTH levels could suggest that an alternate mechanism underlies our findings. Vitamin D deficiency has recently been described as a cardiovascular risk factor and an inverse association between LVMI and $250 H D$ was seen in this cohort (7). However, postoperative changes in cardiovascular indices were not associated with baseline $250 \mathrm{HD}$ levels or change in $250 H D$ levels. The fact that only six subjects were frankly vitamin D deficient $(250 \mathrm{HD}<50 \mathrm{nmol} / \mathrm{l})$ may have prevented us from detecting such an association. Additionally, while mean vitamin D levels increased to the normal range, likely due to postoperative calcium and vitamin D supplementation or liberalized intake thereafter, formal treatment with vitamin D was not a part of this investigation, and $36 \%$ of all patients and four of six vitamin D-deficient patients did not attain levels $>75 \mathrm{nmol} / \mathrm{l}$. A study assessing vitamin D treatment in patients with PHPT and concomitant vitamin D deficiency is necessary to adequately address whether vitamin D deficiency and its repletion affect cardiovascular health in PHPT.

Our study has a number of design limitations, foremost of which is the absence of a longitudinal control group. A randomized controlled trial of PTX vs no surgery would have been a superior design, but we were unable to enroll patients into such a study. Further, the size of the cohort precludes a subgroup analysis to address the issue of differing responses to surgery in those who meet vs those who do not meet criteria for surgery. We may have been limited in detecting improvements in cardiovascular indices due to worsening of other risk factors for atherosclerosis (BMI and CRP increased and GFR declined), although the magnitude of these changes was small. We also cannot rule out the possibility that longer follow-up may have revealed amelioration of structural abnormalities, which could take longer to improve compared with functional measures such as stiffness. Lastly, we cannot definitively attribute the improvement we observed to PTX rather than regression to the mean. Despite these limitations, this study has several notable strengths, including its prospective design, the long duration of follow-up, and the homogeneity of mild PHPT in the cohort. The availability of data on cardiovascular risk factors and $250 \mathrm{HD}$ levels are also strengths. Finally, the broad assessment of cardiovascular structure and function allowed us to see differential effects of PHPT and PTX in different portions of the vascular tree.

In summary, the effect of PTX on subclinical cardiovascular disease in mild PHPT is modest, with a decline in carotid stiffness being the most prominent finding. Cardiovascular abnormalities in PHPT and post-PTX changes were localized primarily within the carotid vascular bed, and benefits of surgery were mostly limited to those with abnormalities at the time of diagnosis. These data provide direction for future research on the cardiovascular effects of PHPT, including the proclivity for affecting the carotid vascular bed, the mechanism of increased vascular stiffness, and the potential role of vitamin D deficiency in the cardiovascular consequences of PHPT. While the declines seen in those with increased carotid stiffness at baseline are impressive, the number of such patients was small, and do not warrant routine use of carotid ultrasonography in the evaluation of patients with PHPT. In conclusion, unlike the skeleton in PHPT, where surgery leads to significant and sustained improvements across skeletal sites, these data do not support a similar global effect on the cardiovascular system. These findings are reassuring with regard to current international guidelines that do not include cardiovascular disease as a criterion for PTX (55).

\section{Declaration of interest}

The authors declare that there is no conflict of interest that could be perceived as prejudicing the impartiality of the research reported.

\section{Funding}

This work was supported by NIH R01 DK066329, K24 DK074457, and UL1 RR024156.

\section{References}

1 Hedback G, Oden A \& Tisell LE. The influence of surgery on the risk of death in patients with primary hyperparathyroidism. World Journal of Surgery 199115 399-405 (discussion 406-397). (doi:10.1007/BF01658740)

2 Palmer M, Adami HO, Bergstrom R, Akerstrom G \& Ljunghall S. Mortality after surgery for primary hyperparathyroidism: a followup of 441 patients operated on from 1956 to 1979. Surgery 1987 $1021-7$.

3 Silverberg SJ, Shane E, Jacobs TP, Siris E \& Bilezikian JP. A 10-year prospective study of primary hyperparathyroidism with or without parathyroid surgery. New England Journal of Medicine 1999341 1249-1255. (doi:10.1056/NEJM199910213411701)

4 Wermers RA, Khosla S, Atkinson EJ, Grant CS, Hodgson SF, O'Fallon WM \& Melton LJ III. Survival after the diagnosis of 
hyperparathyroidism: a population-based study. American Journal of Medicine $1998 \mathbf{1 0 4}$ 115-122. (doi:10.1016/S00029343(97)00270-2)

5 Yu N, Donnan PT \& Leese GP. A record linkage study of outcomes in patients with mild primary hyperparathyroidism: the Parathyroid Epidemiology and Audit Research Study (PEARS). Clinical Endocrinology 201075 169-176. (doi:10.1111/j.1365-2265. 2010.03958.x)

6 Walker MD, Fleischer J, Rundek T, McMahon DJ, Homma S, Sacco R \& Silverberg SJ. Carotid vascular abnormalities in primary hyperparathyroidism. Journal of Clinical Endocrinology and Metabolism 200994 3849-3856. (doi:10.1210/jc.2009-1086)

7 Walker MD, Fleischer JB, Di Tullio MR, Homma S, Rundek T, Stein EM, Zhang C, Taggart T, McMahon DJ \& Silverberg SJ. Cardiac structure and diastolic function in mild primary hyperparathyroidism. Journal of Clinical Endocrinology and Metabolism 201095 2172-2179. (doi:10.1210/jc.2009-2072)

8 Silverberg SJ, Lewiecki EM, Mosekilde L, Peacock M \& Rubin MR. Presentation of asymptomatic primary hyperparathyroidism: proceedings of the third international workshop. Journal of Clinical Endocrinology and Metabolism 200994 351-365. (doi:10.1210/jc. 2008-1760)

9 Iwata I, Walker MD, Di Tullio MR, Hyodo E, Jin Z, Liu R, Sacco RL, Homma S \& Silverberg SJ. Aortic valve calcification in mild primary hyperparathyroidism. Journal of Clinical Endocrinology and Metabolism 201197 132-137. (doi:10.1210/jc.2011-2107)

10 Dalberg K, Brodin LA, Juhlin-Dannfelt A \& Farnebo LO. Cardiac function in primary hyperparathyroidism before and after operation. An echocardiographic study. European Journal of Surgery $1996162171-176$.

11 Nappi S, Saha H, Virtanen V, Limnell V, Sand J, Salmi J \& Pasternack A. Left ventricular structure and function in primary hyperparathyroidism before and after parathyroidectomy. Cardiology 200093 229-233. (doi:10.1159/000007031)

12 Piovesan A, Molineri N, Casasso F, Emmolo I, Ugliengo G, Cesario F \& Borretta G. Left ventricular hypertrophy in primary hyperparathyroidism. Effects of successful parathyroidectomy. Clinical Endocrinology 199950 321-328. (doi:10.1046/j.1365-2265. 1999.00651.x)

13 Stefenelli T, Abela C, Frank H, Koller-Strametz J, Globits S, BerglerKlein J \& Niederle B. Cardiac abnormalities in patients with primary hyperparathyroidism: implications for follow-up. Journal of Clinical Endocrinology and Metabolism $1997 \mathbf{8 2}$ 106-112. (doi:10.1210/jc.82.1.106)

14 Farahnak P, Ring M, Caidahl K, Farnebo LO, Eriksson MJ \& Nilsson IL. Cardiac function in mild primary hyperparathyroidism and the outcome after parathyroidectomy. European Journal of Endocrinology 2010163 461-467. (doi:10.1530/EJE-10-0201)

15 Persson A, Bollerslev J, Rosen T, Mollerup CL, Franco C, Isaksen GA, Ueland T, Jansson S \& Caidahl K. Effect of surgery on cardiac structure and function in mild primary hyperparathyroidism. Clinical Endocrinology 201174 174-180. (doi:10.1111/j. 1365-2265.2010.03909.x)

16 Levy D, Garrison RJ, Savage DD, Kannel WB \& Castelli WP. Prognostic implications of echocardiographically determined left ventricular mass in the Framingham Heart Study. New England Journal of Medicine $1990 \mathbf{3 2 2}$ 1561-1566. (doi:10.1056/ NEJM199005313222203)

17 Gardin JM, McClelland R, Kitzman D, Lima JA, Bommer W, Klopfenstein HS, Wong ND, Smith VE \& Gottdiener J. M-mode echocardiographic predictors of six- to seven-year incidence of coronary heart disease, stroke, congestive heart failure, and mortality in an elderly cohort (the Cardiovascular Health Study). American Journal of Cardiology 200187 1051-1057. (doi:10.1016/S0002-9149(01)01460-6)

18 Mogelvang R, Sogaard P, Pedersen SA, Olsen NT, Marott JL, Schnohr P, Goetze JP \& Jensen JS. Cardiac dysfunction assessed by echocardiographic tissue Doppler imaging is an independent predictor of mortality in the general population. Circulation 2009 119 2679-2685. (doi:10.1161/CIRCULATIONAHA.108.793471)
19 Kohsaka S, Jin Z, Rundek T, Boden-Albala B, Homma S, Sacco RL \& Di Tullio MR. Impact of mitral annular calcification on cardiovascular events in a multiethnic community: the Northern Manhattan Study. JACC Cardiovascular Imaging 2008 1 617-623. (doi:10.1016/j.jcmg.2008.07.006)

20 Chambless LE, Folsom AR, Clegg LX, Sharrett AR, Shahar E, Nieto FJ, Rosamond WD \& Evans G. Carotid wall thickness is predictive of incident clinical stroke: the Atherosclerosis Risk in Communities (ARIC) study. American Journal of Epidemiology 2000 151 478-487. (doi:10.1093/oxfordjournals.aje.a010233)

21 O'Leary DH, Polak JF, Kronmal RA, Manolio TA, Burke GL \& Wolfson SK Jr. Carotid-artery intima and media thickness as a risk factor for myocardial infarction and stroke in older adults. Cardiovascular Health Study Collaborative Research Group. New England Journal of Medicine 1999340 14-22. (doi:10.1056/ NEJM199901073400103)

22 Tsivgoulis G, Vemmos K, Papamichael C, Spengos K, Daffertshofer M, Cimboneriu A, Zis V, Lekakis J, Zakopoulos N \& Mavrikakis M. Common carotid arterial stiffness and the risk of ischaemic stroke. European Journal of Neurology $2006 \mathbf{1 3}$ 475-481. (doi:10.1111/j.1468-1331.2006.01291.x)

23 Polak JF, Shemanski L, O'Leary DH, Lefkowitz D, Price TR, Savage PJ, Brant WE \& Reid C. Hypoechoic plaque at US of the carotid artery: an independent risk factor for incident stroke in adults aged 65 years or older. Cardiovascular Health Study. Radiology 1998208 649-654.

24 Rundek T, Arif H, Boden-Albala B, Elkind MS, Paik MC \& Sacco RL. Carotid plaque, a subclinical precursor of vascular events: the Northern Manhattan Study. Neurology 200870 1200-1207. (doi:10.1212/01.wnl.0000303969.63165.34)

25 Friedewald WT, Levy RI \& Fredrickson DS. Estimation of the concentration of low-density lipoprotein cholesterol in plasma, without use of the preparative ultracentrifuge. Clinical Chemistry 197218 499-502.

26 Matthews DR, Hosker JP, Rudenski AS, Naylor BA, Treacher DF \& Turner RC. Homeostasis model assessment: insulin resistance and $\beta$-cell function from fasting plasma glucose and insulin concentrations in man. Diabetologia 198528 412-419. (doi:10.1007/ BF00280883)

27 Levey AS, Bosch JP, Lewis JB, Greene T, Rogers N \& Roth D. A more accurate method to estimate glomerular filtration rate from serum creatinine: a new prediction equation. Modification of Diet in Renal Disease Study Group. Annals of Internal Medicine 1999130 461-470.

28 Rundek T, Elkind MS, Pittman J, Boden-Albala B, Martin S, Humphries SE, Juo SH \& Sacco RL. Carotid intima-media thickness is associated with allelic variants of stromelysin-1, interleukin-6, and hepatic lipase genes: the Northern Manhattan Prospective Cohort Study. Stroke 200233 1420-1423. (doi:10.1161/01.STR. 0000015558.63492.B6)

29 Juo SH, Lin HF, Rundek T, Sabala EA, Boden-Albala B, Park N, Lan MY \& Sacco RL. Genetic and environmental contributions to carotid intima-media thickness and obesity phenotypes in the Northern Manhattan Family Study. Stroke 200435 2243-2247. (doi:10.1161/01.STR.0000142132.20442.d8)

30 Lang RM, Bierig M, Devereux RB, Flachskampf FA, Foster E, Pellikka PA, Picard MH, Roman MJ, Seward J, Shanewise JS, Solomon SD, Spencer KT, Sutton MS \& Stewart WJ. Recommendations for chamber quantification: a report from the American Society of Echocardiography's Guidelines and Standards Committee and the Chamber Quantification Writing Group, developed in conjunction with the European Association of Echocardiography, a branch of the European Society of Cardiology. Journal of the American Society of Echocardiography $2005 \mathbf{1 8}$ 1440-1463. (doi:10.1016/j.echo.2005.10.005)

31 Devereux RB, Alonso DR, Lutas EM, Gottlieb GJ, Campo E, Sachs I \& Reichek N. Echocardiographic assessment of left ventricular hypertrophy: comparison to necropsy findings. American Journal of Cardiology 198657 450-458. (doi:10.1016/0002-9149(86) 90771-X) 
32 Nagueh SF, Appleton CP, Gillebert TC, Marino PN, Oh JK, Smiseth OA, Waggoner AD, Flachskampf FA, Pellikka PA \& Evangelisa A. Recommendations for the evaluation of left ventricular diastolic function by echocardiography. European Journal of Echocardiography 200910 165-193. (doi:10.1093/ ejechocard/jep007)

33 Cohn JN. Arterial stiffness, vascular disease, and risk of cardiovascular events. Circulation 2006113 601-603. (doi:10.1161/ CIRCULATIONAHA.105.600866)

34 Dolan E, Thijs L, Li Y, Atkins N, McCormack P, McClory S, O'Brien E, Staessen JA \& Stanton AV. Ambulatory arterial stiffness index as a predictor of cardiovascular mortality in the Dublin Outcome Study. Hypertension 200647 365-370. (doi:10.1161/ 01.HYP.0000200699.74641.c5)

35 Benetos A, Thomas F, Joly L, Blacher J, Pannier B, Labat C, Salvi P, Smulyan H \& Safar ME. Pulse pressure amplification a mechanical biomarker of cardiovascular risk. Journal of the American College of Cardiology 2010 55 1032-1037. (doi:10.1016/j.jacc.2009.09. 061)

36 Schillaci G, Pucci G, Pirro M, Monacelli M, Scarponi AM, Manfredelli MR, Rondelli F, Avenia N \& Mannarino E. Largeartery stiffness: a reversible marker of cardiovascular risk in primary hyperparathyroidism. Atherosclerosis 2011 218 96-101. (doi:10.1016/j.atherosclerosis.2011.05.010)

37 Guerin AP, Blacher J, Pannier B, Marchais SJ, Safar ME \& London GM. Impact of aortic stiffness attenuation on survival of patients in end-stage renal failure. Circulation $2001 \mathbf{1 0 3}$ 987-992. (doi:10.1161/01.CIR.103.7.987)

38 Rubin MR, Maurer MS, McMahon DJ, Bilezikian JP \& Silverberg SJ. Arterial stiffness in mild primary hyperparathyroidism. Journal of Clinical Endocrinology and Metabolism 200590 3326-3330. (doi:10.1210/jc.2004-1400)

39 Smith JC, Page MD, John R, Wheeler MH, Cockcroft JR, Scanlon MF \& Davies JS. Augmentation of central arterial pressure in mild primary hyperparathyroidism. Journal of Clinical Endocrinology and Metabolism 200085 3515-3519. (doi:10.1210/jc. 85.10.3515)

40 Rambausek M, Ritz E, Rascher W, Kreusser W, Mann JF, Kreye VA \& Mehls O. Vascular effects of parathyroid hormone (PTH). Advances in Experimental Medicine and Biology $1982 \mathbf{1 5 1}$ 619-632.

41 Hulter HN, Melby JC, Peterson JC \& Cooke CR. Chronic continuous PTH infusion results in hypertension in normal subjects. Journal of Clinical Hypertension 19862 360-370.

42 Stefenelli T, Mayr H, Bergler-Klein J, Globits S, Woloszczuk W \& Niederle B. Primary hyperparathyroidism: incidence of cardiac abnormalities and partial reversibility after successful parathyroidectomy. American Journal of Medicine 199395 197-202. (doi:10.1016/0002-9343(93)90260-V)

43 Cosmi JE, Kort S, Tunick PA, Rosenzweig BP, Freedberg RS, Katz ES, Applebaum RM \& Kronzon I. The risk of the development of aortic stenosis in patients with "benign" aortic valve thickening. Archives of Internal Medicine $2002 \mathbf{1 6 2}$ 2345-2347. (doi:10.1001/ archinte.162.20.2345)

44 Silverberg SJ, Gartenberg F, Jacobs TP, Shane E, Siris E, Staron RB, McMahon DJ \& Bilezikian JP. Increased bone mineral density after parathyroidectomy in primary hyperparathyroidism. Journal of Clinical Endocrinology and Metabolism $1995 \mathbf{8 0}$ 729-734. (doi:10.1210/jc.80.3.729)
45 Nakaoka D, Sugimoto T, Kobayashi T, Yamaguchi T, Kobayashi A \& Chihara K. Prediction of bone mass change after parathyroidectomy in patients with primary hyperparathyroidism. Journal of Clinical Endocrinology and Metabolism $2000 \mathbf{8 5}$ 1901-1907. (doi:10.1210/jc.85.5.1901)

46 Bots ML, Palmer MK, Dogan S, Plantinga Y, Raichlen JS, Evans GW, O'Leary DH, Grobbee DE \& Crouse JR III. Intensive lipid lowering may reduce progression of carotid atherosclerosis within 12 months of treatment: the METEOR study. Journal of Internal Medicine $2009 \mathbf{2 6 5}$ 698-707. (doi:10.1111/j.13652796.2009.02073.x)

47 Crouse JR III, Byington RP, Bond MG, Espeland MA, Craven TE, Sprinkle JW, McGovern ME \& Furberg CD. Pravastatin, lipids, and atherosclerosis in the carotid arteries (PLAC-II). American Journal of Cardiology 199575 455-459. (doi:10.1016/SOOO29149(99)80580-3)

48 Riccioni G, Vitulano N, Mancini B, Zanasi A \& D’Orazio N. Oneyear treatment with rosuvastatin reduces intima-media thickness in 45 hypercholesterolemic subjects with asymptomatic carotid artery disease. Pharmacology 201085 63-67. (doi:10.1159/ $000276476)$

49 Lunder M, Janic M, Jug B \& Sabovic M. The effects of low-dose fluvastatin and valsartan combination on arterial function: a randomized clinical trial. European Journal of Internal Medicine 201223 261-266. (doi:10.1016/j.ejim.2011.11.011)

50 Mizuguchi Y, Oishi Y, Miyoshi H, Iuchi A, Nagase N \& Oki T. Impact of statin therapy on left ventricular function and carotid arterial stiffness in patients with hypercholesterolemia. Circulation Journal 200872 538-544. (doi:10.1253/circj.72.538)

51 Ratchford EV, Gutierrez J, Lorenzo D, McClendon MS, Della-Morte D, DeRosa JT, Elkind MS, Sacco RL \& Rundek T. Short-term effect of atorvastatin on carotid artery elasticity: a pilot study. Stroke 201142 3460-3464. (doi:10.1161/STROKEAHA. 111.625418)

52 Bolland MJ, Grey AB, Gamble GD \& Reid IR. Association between primary hyperparathyroidism and increased body weight: a metaanalysis. Journal of Clinical Endocrinology and Metabolism 200590 1525-1530. (doi:10.1210/jc.2004-1891)

53 Ayturk S, Gursoy A, Bascil Tutuncu N, Ertugrul DT \& Guvener Demirag N. Changes in insulin sensitivity and glucose and bone metabolism over time in patients with asymptomatic primary hyperparathyroidism. Journal of Clinical Endocrinology and Metabolism 200691 4260-4263. (doi:10.1210/jc.2005-2825)

54 Bollerslev J, Rosen T, Mollerup CL, Nordenstrom J, Baranowski M, Franco C, Pernow Y, Isaksen GA, Godang K, Ueland T \& Jansson S. Effect of surgery on cardiovascular risk factors in mild primary hyperparathyroidism. Journal of Clinical Endocrinology and Metabolism 200994 2255-2261. (doi:10.1210/jc.2008-2742)

55 Bilezikian JP, Khan AA \& Potts JT Jr. Guidelines for the management of asymptomatic primary hyperparathyroidism: summary statement from the third international workshop. Journal of Clinical Endocrinology and Metabolism $2009 \mathbf{9 4}$ 335-339. (doi:10.1210/jc.2008-1763)

Received 10 February 2012

Revised version received 29 May 2012

Accepted 1 June 2012 